\title{
Genetic Diversity of Bacteriophage Communities in Napahai Wetland
}

\author{
J.K. Li, C. Sun, S. Li, Y.S.Cui, Y.L. Wei, X.L. Ji* \\ College of Science and Technology, Kunming University of Science and Technology, Kunming, 650500, Yunnan, China
}

\begin{abstract}
Many results have. showed that the great diversity of bacteriophages in various aquatic environments, including marine water, freshwater and paddy water, but few studies was about the genetic diversity of bacteriophages in the wetland. To better understand the genetic diversity of bacteriophages communities of Napahai wetland, we selected viral capsid protein gene (g23) as a gene marker to reveal genetic diversity of bacteriophage in Napahai wetland in Yunnan province of China. The g23 gene fragment of bacteriophage was amplified with the primers MZIA1Bis and MIZA6. In this study, 21 different clones fragments in g23 gene sequences were found. Phylogenetic analysis demonstrated that some g23 genotypes were closely related to the T4-like phages, the others clustered two groups were unknown sequences which had far evolutionary distances with the currently known phages sequences. So the unknown sequences may represent the new particular bacteriophage communities.
\end{abstract}

Keywords-T4-type phage; Napahai wetland; g23 gene; Genetic diversity.

\section{INTRODUCTION}

Viruses are general in various environments and have a great abundance in various environments. Viruses play an important role in regulating the structure and diversity of microbial populations. Because of great amount and biodiversity of viruses, they are considered as the largest genomic reservoir and among them the vast majority are bacteriophages in the natural environments[1] .

The T4-type of phage as an important member of the Myoviridae family have caused widespread concern in the past few year, particularly from ecological scientists[2]. With the development of viral genomics, genetic diversity analysis is considered as a powerful improver on phylogenetic classification and genetic diversity of viruses in various environments[1]. The g23 as a capsid protein gene of T4-type phages will be the most frequently used marker gene for assessing gene-diversity of T4-type bacteriophage[1]. And in the past few years, most molecular reachers on phages in nature have mainly focused on the viruses of marine[3].

Wetlands are a natural genetic library, have characteristics of both land and water and play a number of roles in the environment. The Napahai wetland which located in Shangri-La is a unique seasonal plateau wetland with low latitude and high altitude in Yunnan, China. It is an isolated ecosystem that own distinct rainy and dry seasons. There are a large number of bacteriophages which are one of the most important factors to balance the wetland ecosystem, but the research on phage was still rare in Napahai wetland. In this study, the viral capsid protein gene (g23) was selected as a gene marker to reveal genetic diversity on phage communities of natural environments.

\section{MATERIALS AND METHODS}

\section{A. Napahai wetland water sampling and ultrafiltration}

The sample was collected from the Napahai wetland of Shangri-La (E99 $\left.37^{\circ} 22^{\prime \prime}, \mathrm{N} 27^{\circ} 53^{\prime} 32^{\prime \prime}, 3266 \mathrm{~m}, \mathrm{pH} 6.6\right)$ in 2013. Water samples were kept in dark at $4^{\circ} \mathrm{C}$.

Centrifuged water samples at $8000 \mathrm{~g}$ for $30 \mathrm{~min}$ at $4^{\circ} \mathrm{C}$ to remove soil particles, plankton etc. Then filtrated the water samples with a $0.45 \mu \mathrm{m}$ and $0.22 \mu \mathrm{m}$ cellulose membrane to remove other bacteria. Concentrates of virus were stored in the dark at $4^{\circ} \mathrm{C}[4]$.

\section{B. DNA extraction and PCR amplification}

The treated water samples were frozen in liquid nitrogen or $-80^{\circ} \mathrm{C}$ frozen $8 \mathrm{~h}$, nozzle after laminating pierce holes. The lyophilized overnight freeze-dried into powder, DNA was extracted with the OMEGA virus genome extraction kit.

The viral capsid protein gene g23, was amplified using the primers MZIA1Bis and MIZA6[5]. Fifty microliter of PCR mixture contained $1 \mu \mathrm{L}$ of forward and reverse primers(10pmol each), 1 2 $\mu \mathrm{L}$ of DNA template, $5 \mu \mathrm{L}$ of $\mathrm{dNTP}(2.5 \mathrm{mM}$ each), $0.5 \mu \mathrm{L}$ of Ex-Taqpolymerse, and 5 $\mu \mathrm{L}$ of Ex-Taqbuffer and was filled up to the required volume $(36.7-37.7 \mu \mathrm{L})$ with MilliQ water. PCR products were performed with the following cycle parameters: denaturation at $94^{\circ} \mathrm{C}$ for $4 \mathrm{~min}, 35$ cycles of denaturation at $94^{\circ} \mathrm{C}$ for $45 \mathrm{~s}$, annealing at $45^{\circ} \mathrm{C}$ for $45 \mathrm{~s}$, ramping at $0.5^{\circ} \mathrm{Cs}-1$, and extension at $72^{\circ} \mathrm{C}$ for $45 \mathrm{~s}$, a final extension at $72^{\circ} \mathrm{C}$ for $10 \mathrm{~min}$.

\section{Sequence analysis}

The g23 positive clones were analyst by using the BLAST search tool at NCBI (http: //www. ncbi.nlm.nih.gov/ ). A neighbor-joining tree was founded by Molecular Evolutionary Genetic Analysis software (MEGA 3.0) [6] with 1000-fold bootstrap support.

\section{RESULTS}

\section{A. DNA extraction}

The treated water samples were extracted with the PCI solution (phenol:chloroform:isoamylalcohol=25:24:1,v/v) and once with CIA solution

(chloroform:isoamylalcohol $=24: 1, \mathrm{v} / \mathrm{v}$ ), and DNA was contaminated by the other proteins. So the OMEGA virus genome extraction kit was used to extract DNA. 


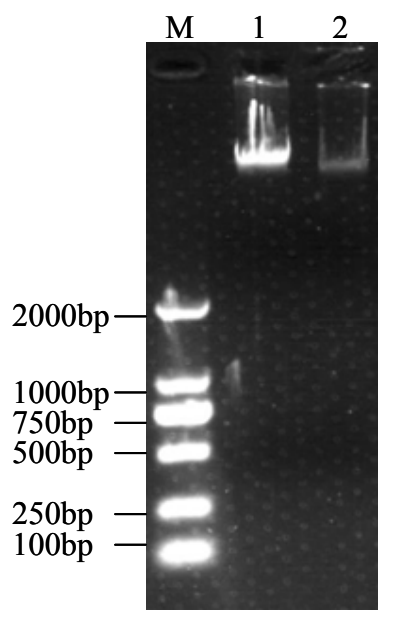

Figure 1. Concentrated phage metagenome of NPHW-2 in May 2013.

M: DNA markers;1:phage metagenome(extracted with phenol/ chloroform method);

2:phage metagenome(extracted with OMEGA virus genome extraction kit)

\section{B. PCR amplification}

The primer was designed to detect the T4-type phage in Napahai wetland ,then the viral capsid protein gene, g23, was amplified with the primers MZIA1Bis and MIZA6. About 500-bp PCR products were obtained from all samples, and the best annealing temperature was $50^{\circ}$ C.(Fig. 2 ).

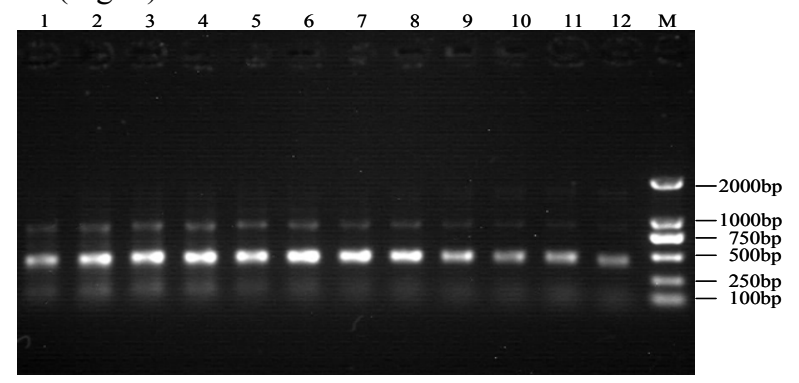

Figure 2. Temperature gradient amplification of concentrated phage of Napahai wetland with primers MZIAlbis/MZIA6

\section{Phylogenetic diversity of T4-type phages isolates}

In this study,as shown in Fig.3, many g23 clones formed several clusters separate from those of floodwater origins, This finding clearly showed that many g23 genes in this study differed from those obtained from marine and freshwater environments[7], which was consistent with our assumes that g23 sequences in wetland were unique and different from those of marine and freshwater origins. The tree demonstrated that the homology similarity among T4-type phages and clone2,clone12 and clone 30 were $81 \%, 85 \%$ and $86 \%$, respectively. About 11 g23 fragments from Napahai wetland formed clusters which were different from those of marine and freshwater environments. And the remainders were similar with the Uncultured phage clone from Antarctic Lake and Kotokel
Lake.

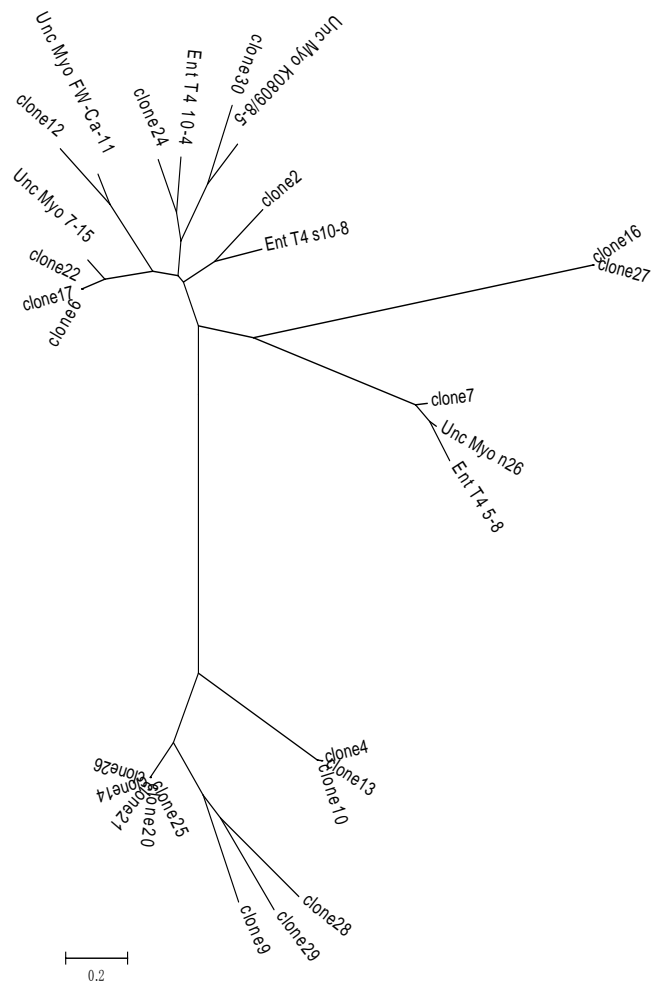

Figure 3. Phylogenetic relationships among the clones amplification of concentrated phage of Napahai wetland with primers MZIA1bis/MZIA6

\section{DISCUSSION}

Viruses are extremely abundant in lakes and oceans, yet little is known about the composition of these viral communities. In particular, the distribution of genotypes is virtually unexplored for bacteriophages[8]. This study investigated the genetic diversity of bacteriophage communities in Napahai wetland. In this study, sequence analyses of the viral g23 gene have been used to analyze the diversity of natural assemblages of wetland bacteriophages. First File'e [8]gained gene fragments ranging from 380 to $600 \mathrm{bp}$ from marine samples. In addition, Jia et al. [2] and Fujii et al. obtained PCR products in a range from 415 to $614 \mathrm{bp}$ in the Anjo paddy field and from 422 to $644 \mathrm{bp}$ in the Omagari paddy field[7]. Guanghua Wang et al.[7]obtained PCR products ranging from 350 to $599 \mathrm{bp}$. The length was about $500 \mathrm{bp}$ in this study. These findings indicate that g23 genes are widely variable in length in marine and soil environments, probably reflecting the great diversity of phage communities in those environments[7].

In this paper, some of the clones obtained in this study formed several small clusters with clones that were ungrouped in previous studies[7] by HUANG Hui-Zhen et al.[9],there were also some had some homology with the previous studies by Tatyana $\mathrm{V}$ et al.[10] and Alberto López-Bueno et al.[11].We speculated that Napahai wetland were similar with Lake Kotokel and Antarctic Lake, which all located in high latitudes and they were 
had the similar low temperature environments. Finally, there were about half of clones had no homology with the sequences obtained in the database. They are the unique phages communities in Napahai wetland.

In conclusion, this study indicated that rich diversity of bacteriophages existed in Napahai wetland. And there were many unique phages in Napahai wetland which were different from those in marine, freshwater environments. Further studies on the covariation of the genetic diversity of virus and host populations with changing environmental variables would provide new insights into the ecological roles of wetland viruses.

\section{V.ACKNOWLEDGMENTS}

This research was supported the National Natural Science Foundation of China (31160121), and State Key Laboratory of Microbial Resources, Institute of Microbiology, Chinese Academy of Sciences (SKLMR-20110606).

\section{REFERENCES}

[1] Fujii, T., Nakayama, N., Nishida, M., Sekiya, H., Kato, N., Asakawa, S.\&Kimura, M. Novel capsid genes (g23) of T4-type bacteriophages in a Japanese paddy field. Soil Biol Biochem 40, 1049-1058,2008.

[2] Jia, Z. J., Ishihara, R., Nakajima, Y., Asakawa, S.\&Kimura, M. Molecular characterization of T4-type bacteriophages in a rice field. Environmental Microbiology 9, 1091-1096,2007.

[3] Paul, J. H.\&Sullivan, M. B. Marine phage genomics: what have we learned? Curr Opin Biotech 16, 299-307,2005.

[4] Ruiyong Jing, Junjie Liu, Zhenhua Yu, Xiaobing Liu,and Guanghua Wang. Phylogenetic Distr ibution of the Capsid Assem bly Protein Gene (g20) of Cyanophages in Paddy Floodwater s in Nor theast China, PLoS ONE9, 1-11,2014.

[5] Filee, J., Tetart, F.,Suttle, C., A.Krisch, H. M..Marine T4-type bacteriophages, a ubiquitous component of the dark matter of the biosphere. P Natl Acad Sci USA 102, 12471-12476,2005.

[6] Kumar, S., Tamura, K.\&Nei, M. MEGA3: Integrated software for molecular evolutionary genetics analysis and sequence alignment. Brief Bioinform 5, 150-163,2004.

[7] Wang, G. H., M.Saito, M.Tsuchiya, K.Asakawa, S.Kimura, M. Survey of major capsid genes (g23) of T4-type bacteriophages in Japanese paddy field soils. Soil Biol Biochem 41, 13-20,2009.

[8] Cindy M.Short and Curtis A.Suttle Nearly Identical Bacteriophage Structural Gene Sequences Are Widely Distributed in both Marine and Freshwater Environments Applied and Environmental Microbiology 71,480-486,2005

[9] HUANG Hui-Zhen, C. K., XU Min, ZHAO Yi-Jun. Genetic diversity of T4 virioplankton, inferred from g23 gene, in Wuhan Donghu Lake. CHINA. ENVIRONMENTAL SCIENCECE 31, 443-447,2011.

[10] Tatyana V, B. O. I., Belykh•Sergey A, Potapov•Ekaterina G, Sorokovikova. Diversity of the major capsid genes (g23) of T4-like bacteriophages in the eutrophic Lake Kotokel in East Siberia, Russia. Arch Microbiol 195, 513-520,2013.

[11] Lopez-Bueno, A., Tamames, J., Velazquez, D., Moya, A., Quesada, A.\&Alcami, A. High Diversity of the Viral Community from an Antarctic Lake. Science 326, 858-861,2009. 